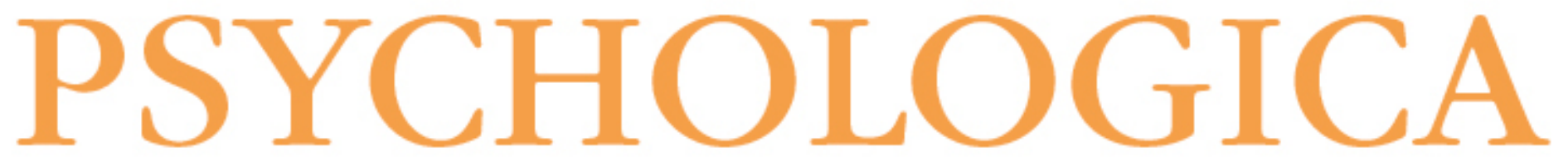

\title{
O efeito mediador da regulação emocional na relação entre a expressividade emocional da família de origem e as reacções maternas à expressão de emoções positivas das crianças
}
Autor(es):
Palmeira, Lara; Gouveia, José Pinto; Dinis, Alexandra; Lourenço, Sara; Veloso, Mário

Publicado por: Imprensa da Universidade de Coimbra

URL persistente:

URI:http://hdl.handle.net/10316.2/3479

DOI:

DOI:http://dx.doi.org/10.14195/1647-8606_52-2_18

Accessed : $\quad$ 26-Apr-2023 15:50:29

A navegação consulta e descarregamento dos títulos inseridos nas Bibliotecas Digitais UC Digitalis, UC Pombalina e UC Impactum, pressupõem a aceitação plena e sem reservas dos Termos e Condições de Uso destas Bibliotecas Digitais, disponíveis em https://digitalis.uc.pt/pt-pt/termos.

Conforme exposto nos referidos Termos e Condições de Uso, o descarregamento de títulos de acesso restrito requer uma licença válida de autorização devendo o utilizador aceder ao(s) documento(s) a partir de um endereço de IP da instituição detentora da supramencionada licença.

Ao utilizador é apenas permitido o descarregamento para uso pessoal, pelo que o emprego do(s) título(s) descarregado(s) para outro fim, designadamente comercial, carece de autorização do respetivo autor ou editor da obra.

Na medida em que todas as obras da UC Digitalis se encontram protegidas pelo Código do Direito de Autor e Direitos Conexos e demais legislação aplicável, toda a cópia, parcial ou total, deste documento, nos casos em que é legalmente admitida, deverá conter ou fazer-se acompanhar por este aviso. 


\section{NÚMERO 52}

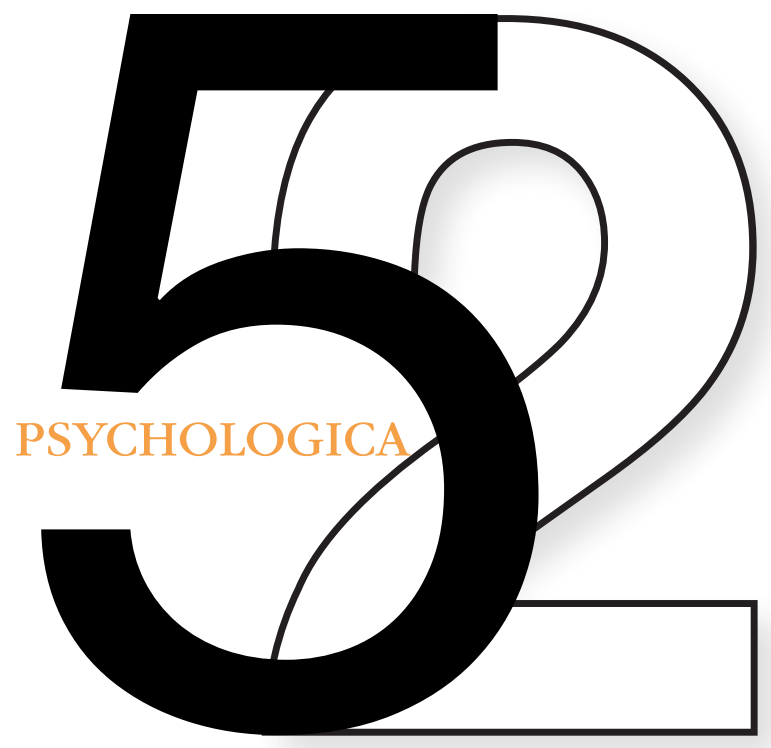

VOLUME II

IMPRENSA DA UNIVERSIDADE DE COIMBRA

FACULDADE DE PSICOLOGIA E DE CIÊNCIAS DA EDUCAÇÃo DA UNIVERSIDADE DE COIMBRA 


\title{
O efeito mediador da regulação emocional na relação entre a expressividade emocional da família de origem e as reacções maternas à expressão de emoções positivas das crianças
}

\begin{abstract}
Lara Palmeira', José Pinto Gouveia², Alexandra Dinis³, Sara Lourenço4 \& Mário Velosos
O papel fundamental da família, especialmente dos pais, enquanto agentes de socialização das emoções tem sido salientado na literatura. De facto, as práticas parentais estabelecem-se, desde cedo, como um meio privilegiado para a identificação e compreensão das emoções, aprendizagem da expressão e de estratégias de regulação emocional. O presente estudo pretende indagar acerca do efeito mediador das estratégias de regulação emocional de 169 mães de crianças dos 8 aos 12 anos de idade, na relação entre o seu ambiente familiar na infância e o modo como reagem à expressão emocional positiva dos seus filhos. Neste sentido, deste estudo sobressaem evidências da existência de um efeito transgeracional do processo de socialização de emoções, verificando-se que as estratégias de regulação emocional das mães funcionam como mediadores da relação entre a expressividade emocional da família de origem e as reacções maternas à expressão de emoções positivas das crianças.
\end{abstract}

PALAVRAS-CHAVE: Expressividade familiar; Socialização das emoções; Regulação emocional; Reacções maternas

\section{Introdução}

As emoções, de acordo com Gross (1998), assumem-se como tendências multidimensionais de resposta formadas a partir da avaliação de pistas emocionais,

\footnotetext{
1 Centro de Investigação do Núcleo de Estudos e Intervenção Cognitivo-Comportamental (CINEICC) larapalmeira@gmail.com

2 CINEICC - Faculdade de Psicologia e de Ciências da Educação da Universidade de Coimbra - jpgouveia@ fpce.uc.pt

3 CINEICC - Faculdade de Psicologia e de Ciências da Educação da Universidade de Coimbra 4 Mestre em Psicologia - Faculdade de Psicologia e de Ciências da Educação da Universidade de Coimbra 5 Mestre em Psicologia - Faculdade de Psicologia e de Ciências da Educação da Universidade de Coimbra
} 
sofrendo, posteriormente, um processo de modelação que ajusta definitivamente a resposta emocional.

A literatura da especialidade destaca o contexto familiar, onde as interacções familiares, especialmente com os agentes de socialização das emoções (pais), contribuem para o reconhecimento, compreensão e expressão das emoções e para a aprendizagem de estratégias de regulação emocional. Neste sentido, os estilos e práticas parentais de socialização das emoções, os quais são influenciados por uma multiplicidade de variáveis (e.g. esquemas emocionais, reacções à expressão emocional da criança, filosofia meta-emocional e a expressividade emocional familiar), são indissociáveis do desenvolvimento das capacidades socioemocionais das crianças e, consequentemente, da maturação e desenvolvimento psicológico destas.

A socialização parental das emoções é um processo multidimensional e abrangente, o qual alude ao papel parental e à sua tradução em crenças, objectivos e valores referentes à experiência, expressão e modelamento emocional da criança. Este fenómeno encontra-se intimamente associado às capacidades emocionais e repercute-se ao nivel da maturação sócio-emocional, do desenvolvimento de competências de cariz emocional e social e da manifestação de quadros psicopatológicos (Eisenberg, Cumberland \& Spinard, 1998).

Eisenberg e colaboradores (1998) apresentaram uma conceptualização teórica da socialização das emoções, salientando os efeitos de feedback existentes entre as competências sócio-emocionais e as consequências do processo de socialização das emoções. O modelo distingue quatro modalidades da socialização parental das emoções, designadamente a expressividade emocional parental, a discussão parental das emoções, as reacções dos pais face à expressão emocional da criança e a selecção ou modificação da situação cujos efeitos podem ser indirectos e directos na experiência, expressão, compreensão e regulação emocional da criança (Valiente \& Eisenberg, 2006).

Mais uma vez são os pais, enquanto figuras significativas, que fomentam e possibilitam a maturação das competências e capacidades emocionais das crianças, uma vez que a validação emocional destas, aliada ao encorajamento da identificação e discriminação emocional, traduzem, por um lado, uma maior diferenciação, aceitação e ventilação das emoções e, por outro lado, a adopção de estratégias mais elaboradas de regulação emocional. Em suma, as consequências deste processo nas crianças reflectem indicadores de ajustamento psicológico e de comportamentos pró-sociais (Melo, 2005).

Importa ainda salientar que este processo parental de socialização emocional assenta numa base de interacções múltiplas, ou seja, encontra-se dependente das características dos pais (e.g. valores, filosofia de educação da criança, regulação 
parental e emocionalidade), da criança (e.g. idade, sexo, temperamento, reactividade e reacções à disciplina) e do contexto sócio-cultural em que estão inseridos (e.g. valores culturais acerca da expressão das emoções ou o papel das práticas parentais na educação da criança), sendo estas influências mútuas e complexas (Valiente \& Eisenberg, 2006).

O contexto emocional familiar e, mais concretamente, a expressividade emocional a ele subjacente, representa o método mais indirecto de socialização das emoções. Deste modo, a expressividade poderá compreender-se como um padrão persistente ou estilo de exibição de expressões verbais e não verbais que, muitas vezes, apresentam uma estreita relação com as emoções. A expressividade emocional poderá assumir diferentes valências, nomeadamente positiva ou negativa e dominante ou submissa (Halberstad, 1991 cit. in Parker, 2006).

O desenvolvimento das capacidades de regulação emocional das crianças (Eisenberg et al., 2001) e a formação dos esquemas infantis acerca do mundo, das emoções e da sua expressão (Dunsmore \& Halberstadt, 1997) radica em diferentes indicadores da variável expressividade emocional familiar, tais como a frequência, intensidade e duração. Por sua vez, pressupõe-se a expressividade emocional do sujeito radica nos esquemas emocionais por ele formados e nos processos de regulação emocional que utiliza, pelo que estes indicadores poderão cumprir uma função de mediação da expressividade familiar (Baker \& Crnic, 2005).

Um ambiente familiar propício à expressão das emoções poderá modelar a criança a fazê-lo, ao invés, a ausência deste ambiente poderá contribuir para a adopção da supressão emocional enquanto estratégia reguladora das emoções. Acresce ainda que a rigidificação dos mecanismos de regulação emocional e a sua generalização a diferentes contextos poderá comprometer a sua funcionalidade, pelo que a descoberta e implementação de outras estratégias se assume como uma importante tarefa desenvolvimental (Dunsmore \& Halberstadt, 1997).

A expressividade emocional familiar repercute-se no funcionamento infantil, uma vez que influencia não só a capacidade da criança para rotular e compreender as suas próprias emoções como as dos outros. Mais se indica que os pais, ao expor a criança a uma diversidade de emoções, estão a contribuir para que esta possa atribuir significados aos acontecimentos, à interacção e às respostas emocionais dos outros (Eisenberg et al., 1998). Dunsmore e Halberstadt (1997) acrescentam que os padrões familiares de expressividade emocional familiar levam a que a criança desenvolva expectativas normativas acerca do que é a experiência e a expressão emocional. Esta influência familiar é extensivel às conceptualizações que as crianças fazem da sua experiência, em virtude do modelamento exercido pelas atribuições familiares e crenças acerca das experiências e expressão emocional e pelas determinantes culturais associadas à expressividade emocional. 
Parece existir uma relação directa entre expressividade familiar positiva e indicadores infantis de comportamento pró-social, popularidade, conhecimento acerca da expressão emocional e compreensão das emoções dos outros, menores níveis de agressão, melhor ajustamento e resiliência face ao stress (Eisenberg et al., 2001; Halberstadt et al., 1999 cit. in Parker, 2006).

Em contraste, um ambiente familiar pautado por expressividade emocional negativa parece comprometer a competência social e contribuir para a existência de elevados níveis de agressão nas crianças (Eisenberg et al., 1998; Halberstadt e colaboradores (1999) cit. in Parker, 2006). De um modo geral, verifica-se que a expressividade emocional negativa dos pais, quando dirigida à criança, poderá indiciar baixo funcionamento social e menores níveis de compreensão emocional. Não obstante, os resultados para emoções negativas mais subtis (e.g. ansiedade e tristeza) não apresentam resultados tão expressivos, sendo que alguns autores consideram que a exposição moderada a níveis apropriados de emoções negativas poderá surtir um efeito benéfico na capacidade infantil de regulação emocional (Hoffman, 2000 cit. in Eisenberg et al., 2003).

As investigações sugerem a influência da expressividade familiar no desenvolvimento da criança. Contudo escassos são os conhecimentos relativos aos possiveis preditores destes comportamentos parentais. Num estudo, Baker e Crnic (2005) verificaram que a expressividade emocional da família de origem, relatada pelas mães, demonstrou ser um factor de relevo na compreensão dos comportamentos maternos de socialização das emoções. De um modo geral, os autores verificaram que as mães que recordavam ambientes de expressividade emocional marcadamente negativos e hostis na família de origem, apresentaram mais dificuldades no suporte, compreensão e regulação dos estados emocionais negativos das suas crianças.

Por outro lado, as reacções parentais face à expressão de emoções, principalmente às negativas, são o factor que mais atenção empírica tem recebido (Eisenberg, Fabes \& Murphy, 1996). Desta forma, a produção científica salienta que, de um modo geral, as reacções parentais negativas a emoções como medo, raiva ou tristeza podem traduzir niveis inferiores de competência social e maior desajustamento emocional para a criança (Roberts \& Strayer, 1987; Eisenberg et al., 1996; Gottman, Katz \& Hooven, 1996). Eisenberg e colaboradores (1996) defenderam que comportamentos inapropriados e/ou desregulados das crianças poderão ser produto duma elevada activação emocional destas face a respostas parentais negativas.

A literatura da especialidade é consensual no que concerne ao impacto disruptivo que as respostas parentais negativas à expressão de emoções de cariz negativo das crianças têm no desenvolvimento infantil. Estas consequências são transversais a diversos domínios, nomeadamente, capacidades reduzidas de coping adaptativo 
e recurso a estratégias de evitamento (Eisenberg et al., 1996), escassez de comportamentos pró-sociais, baixa popularidade e a problemas de externalização relatados por pais e professores (Eisenberg, Fabes, Shepard, Guthrie, Murphy, \& Reiser, 1999), menor compreensão emocional (Pearlman, Camras \& Pelphey, 2008), ventilação emocional insuficiente perante situações indutoras de raiva (Fabes, Leonard, Kupanoff \& Martin, 2001) e maior agressividade na interacção com os pais (Carson \& Parke, 1996 cit. in Melo, 2005).

Por seu turno, no que concerne às respostas positivas dos pais, os dados disponíveis revelam resultados menos consistentes. Não obstante, e de um modo geral, os dados empíricos aludem a que níveis moderados de encorajamento e aceitação parental da expressão emocional positiva e negativa poderão ser indicadores do desenvolvimento sócio-emocional positivo da criança, contribuindo para uma maior consciência dos diferentes estados emocionais e para a uma mais eficaz regulação emocional (Eisenberg et al., 1998), associando-se a comportamentos sociais mais competentes (Denham, Mitchell-Copeland, Strandberg, Auerbach, \& Blair, 1997).

Relativamente às emoções positivas, a literatura é menos vasta, sendo este um campo que necessita de mais investigações. Melo (2005), num estudo na população portuguesa, verificou que as reacções maternas negativas à expressão de emoções positivas dos seus filhos se associaram à raiva temperamental da criança e a sintomatologia depressiva, enquanto as respostas negativas de ambos os progenitores se associaram a estratégias negativas de controlo por esforço, bem como a sintomas de externalização. Estes resultados sublinham a importância de se avaliar não só as reacções parentais às emoções negativas mas também às positivas.

O conceito de regulação emocional tem sido alvo de interesse da psicologia desenvolvimental (Eisenberg, Champion, \& Ma, 2004), pelo que a sua operacionalização e total conhecimento enquanto fenómeno ainda se encontra numa fase muito embrionária.

Gross e colaboradores (2006) definem regulação emocional como uma função destinada à regulação dos afectos e, consequentemente, envolve a modificação de algum componente da interacção entre o sujeito e o ambiente. Este autor acrescenta ainda que este constructo compreende em si os processos que coordenam as alterações nas emoções que os indivíduos experienciam (tipo e momento) e a suas modalidades de expressão. Estas alterações são transversais à natureza, tempo de activação, duração e intensidade das emoções (Gross, 1998). Importa ainda referir que a regulação emocional pode ainda subdividir-se em dois cenários, nomeadamente, um em que se procede à alteração da emoção e um segundo que remete para a emoção como uma determinante da regulação de outros processos - cognitivos, comportamentais, afectivos e relacionais (Cole, Martin 
\& Dennis, 2004). Eisenberg e Spinrad (2004; Eisenberg, Champion, \& Ma, 2004) consideram que este conceito é multidimensional e poderá englobar diferentes processos, nomeadamente, iniciar, evitar, inibir, manter ou modelar a ocorrência, forma, intensidade ou duração dos estados afectivos internos, fisiológicos decorrentes das emoções, dos processos atencionais e motivacionais e, ainda, a tradução comportamental das emoções. Esta conceptualização compreende este processo como um meio para cumprir determinadas funções, designadamente, facilitar a obtenção de objectivos individuais e atingir um estado de adaptação emocional não só biológica, mas também social.

A par com os esquemas emocionais, uma regulação emocional eficaz é um prérequisito para um funcionamento adaptativo (Gross, Richards, \& John, 2006). Neste sentido, um processo ineficaz de regulação emocional poderá traduzir alguma disfuncionalidade na vida do indivíduo (Gross \& Munoz, 1995 cit. in Gratz \& Roemer, 2004; Simpson, Hughes \& Snyder, 2006). Efectivamente, tem-se verificado que défices na regulação emocional podem levar a consequências críticas não só a nível das relações sociais, mas também a nível da saúde mental e física (Mikolajozak, Nelis, Hansenne, \& Quoidbach, 2008). Na verdade, trabalhos recentes sugerem que indivíduos diagnosticados com perturbações de humor ou perturbações ansiógenas manifestam dificuldades na regulação das suas emoções, destacando-se as limitações na identificação e compreensão das mesmas (especialmente as negativas) e a existência de comportamentos disfuncionais como resposta aos estados emocionais (Mennin, Heimberg, Turk \& Fresco, 2005 cit. in Campbell-Sills \& Barlow, 2007).

Em suma, da revisão da literatura, conclui-se que escassos estudos se têm focado nas consequências desenvolvimentais das práticas parentais de socialização de emoções na adultez, bem como na relação entre a expressividade emocional da família de origem e o modo como em adultos, os pais tendem a socializar as emoções dos filhos. Na verdade, as experiências adversas vividas na infância, pautadas pela escassez de cuidado/afecto e excessiva protecção/controlo afectam os processos de maturação psicobiológica e têm-se constituído como factor de risco de relevo no desenvolvimento de psicopatologia na idade adulta. Concomitantemente, também a escassez de cuidado e afecto dos cuidadores primários, tem sido associada a menor ajustamento e maior vulnerabilidade para a psicopatologia (Gilbert et al., 2003).

O presente estudo tem como principal objectivo averiguar a eventual existência de um efeito mediador das estratégias de regulação emocional maternas na relação entre a expressividade emocional na família de origem e o modo como, em adultas, estas mães tendem a reagir às emoções positivas das suas crianças. Assim, acreditamos que mães que na infância vivenciaram um ambiente de expressividade emocional positivo, tenham desenvolvido estratégias de regulação 
emocional mais funcionais, reagindo de modo mais construtivo perante a expressão de emoções positivas dos seus filhos, auxiliando-os no reconhecimento das emoções e na procura de estratégias eficazes de regulação emocional.

\section{Metodologia}

\subsection{Descrição da Amostra}

No presente estudo utilizou-se uma amostra da população geral, constituída por mães de crianças dos 8 aos 12 anos de idade do distrito de Coimbra. Os critérios de exclusão dos participantes foram os seguintes: (a) mães cujas habilitações literárias fossem inferiores ao $4^{\circ}$ ano de escolaridade ou que tivessem dificuldades que comprometessem a leitura e compreensão dos itens que constituíam as escalas, (b) preenchimento incompleto do protocolo de investigação.

Em relação à amostra final, esta ficou constituída por 169 mães (c.f. quadro 1). A média de idades das mães foi de 39.79 ( $D P=4.54)$, sendo que a maioria $(73,4 \%)$ têm idades compreendidas entre os 36 e os 44 anos. Relativamente ao número de anos de escolaridade, as mães distribuem-se entre 4 e 23 anos de frequência académica ( $M=13.34 ; D P=4.34)$, sendo que $63,9 \%$ das mães têm entre 12 a 17 anos de escolaridade. A maioria das mães é casada $(82,2 \%)$ e pertence ao nível sócioeconómico médio $(62,1 \%)$.

Quadro 1 - Características gerais da amostra $(\mathrm{N}=169)$

\begin{tabular}{|c|c|c|c|c|c|c|}
\hline & & & $\mathrm{N}$ & $\%$ & $M$ & DP \\
\hline \multirow{20}{*}{ 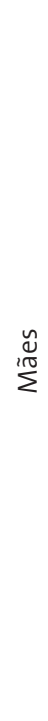 } & \multirow{5}{*}{ Idade } & $29-33$ & 15 & 8.9 & \multirow{5}{*}{39.79} & \multirow{5}{*}{4.54} \\
\hline & & $34-38$ & 46 & $27 \cdot 3$ & & \\
\hline & & $39-43$ & 79 & 46,8 & & \\
\hline & & $44-48$ & 23 & 13,7 & & \\
\hline & & $49-53$ & 6 & 3.6 & & \\
\hline & \multirow{7}{*}{ Anos de Escolaridade } & $4-6$ & 22 & 13.0 & \multirow{7}{*}{13.34} & \multirow{7}{*}{4.34} \\
\hline & & $7-9$ & 13 & 7.8 & & \\
\hline & & $10-12$ & 44 & 26.1 & & \\
\hline & & $13-15$ & 5 & 3.0 & & \\
\hline & & $16-18$ & 80 & 47.4 & & \\
\hline & & $19-21$ & 4 & 2.4 & & \\
\hline & & $22-24$ & 1 & 0.6 & & \\
\hline & \multirow{5}{*}{ Estado Civil } & Solteira & 5 & 3.0 & & \\
\hline & & Casada & 139 & 82.2 & & \\
\hline & & Divorciada & 17 & 10.1 & & \\
\hline & & Viúva & 5 & 3.0 & & \\
\hline & & União de Facto & 3 & 1.8 & & \\
\hline & \multirow{3}{*}{ Nível Socioeconómico } & Baixo & 42 & 24.9 & & \\
\hline & & Médio & 105 & 62.1 & & \\
\hline & & Alto & 22 & 13.0 & & \\
\hline
\end{tabular}




\subsection{Procedimentos}

O contacto com as mães foi efectuado através das escolas frequentadas pelos seus filhos ( $1^{\circ}$ Jardim-Escola João de Deus, Instituto de Almalaguês, Colégio de São José, Instituto Educativo de Lordemão, Agrupamento de Escolas da Lousã e Agrupamento de Escolas de Miranda do Corvo). Às que concordaram em participar, foi enviado o respectivo protocolo num envelope, precedido de uma folha de rosto com uma breve explicação dos objectivos do estudo e algumas questões sobre as características sócio-demográficas, salvaguardando o carácter anónimo e a confidencialidade dos dados. Após o preenchimento, os protocolos foram devolvidos à escola num envelope fechado.

\subsection{Instrumentos}

Cada sujeito completou o protocolo constituído por vários questionários de autoresposta, sendo que para o presente estudo se utilizaram o Family Expressivity Questionaire (FEQ: Halberstadt, 1986; Tradução e Adaptação: Pinto Gouveia, Dinis \& Xavier, 2007), o Trait Meta-Mood Scale (TMMS, Salovey, Mayer, Goldman, Turvey, \& Palfai, 1995; Tradução e Adaptação: Pinto Gouveia, \& Dinis, 2006, manuscrito não publicado) e o Questionário de Coping com as Emoções Positivas - Pais (OQCEPP, Melo, Moreira \& Soares, 2005)

Family Expressivity Questionnaire (FEQ, Halberstadt, 1986; Tradução e Adaptação: Dinis, Pinto Gouveia, \& Xavier, 2010). Este questionário procura avaliar o grau de expressividade presente em diferentes famílias. Para isso, apresentam-se 40 afirmações (itens) através das quais se pretende obter informação sobre a frequência com que são expressas emoções nas famílias. Este questionário implica que o sujeito se reporte à sua infância e adolescência, apontando a frequência com que as situações descritas ocorreram comparativamente com outras famílias. As respostas são dadas numa escala, em que 1 corresponde a "nada frequente na minha família" e 9 a "muito frequente na minha família". A escala original apresenta quatro subescalas, cada uma com 10 itens e compostas por duas dimensões afectivas (positiva/negativa) que se cruzam com duas dimensões de poder (dominante/submissa) da seguinte forma: positiva-dominante; positva-submissa; negativa-dominante; e negativa-submissa (Halberstadt, 1986). No seu estudo, a autora encontrou os seguintes valores de consistencia interna: 87 na subescala positiva-dominante, .88 na positiva-submissa, .88 na negativa-dominante, e .75 na negativa-submissa (Halberstadt, 1986).

Na versão portuguesa do FEQ (Dinis, Pinto Gouveia, \& Xavier, 2010), foram apenas utilizadas duas dimensões, uma de expressividade positiva $\left(\alpha_{\text {cronbach }}=.93\right)$, incluindo ambas as dimensões (dominante e submissa) e outra de expressividade negativa 
$\left(\alpha_{\text {cronbach }}=.88\right)$ composta pelas duas dimensões (dominante e submissa), sendo que a escala a presentou uma boa validade, convergente, divergente e discriminante. No presente estudo as duas dimensões do FEQ apresentaram valores de consistência interna semelhantes aos do estudo de aferição, nomeadamente: .93 na dimensão de expressividade positiva e .88 para a expressividade negativa.

Trait Meta-Mood Scale (TMMS, Salovey, Mayer, Goldman, Turvey, \& Palfai, 1995; Tradução e Adaptação: Pinto Gouveia, \& Dinis, 2006). Este escala é uma medida da inteligência emocional percebida, definida como a habilidade individual para prestar atenção aos estados emocionais, discriminar, clarificar e regular as emoções. É entendida como uma capacidade para reparar os estados emocionais negativos e manter os positivos. Em particular, a TMMS é uma medida de autorelato, desenhada para aceder às crenças individuais que cada um tem acerca das suas competências emocionais. Portanto, esta medida avalia as diferenças individuais, relativamente estáveis, na tendência que as pessoas têm para lidar com os seus estados emocionais e emoções, fazer a distinção clara entre eles e regulá-los. (Salovey et al., 1995).

Aos sujeitos é pedido que avaliem o grau em que estão de acordo com cada um dos itens numa escala de tipo Likert de 5 pontos, desde "discordo totalmente" (1) a "concordo plenamente" (5).

Na sua versão original, este instrumento é composto por 48 itens (Salovey et al., 1995), organizados nesta estrutura de 3 factores - Atenção às emoções, Clareza de sentimentos e Reparação do estado emocional -, com consistências internas de $.86, .87$ e .82 , respectivamente. Na versão reduzida, de 30 itens (Salovey et al., 1995), os autores encontraram índices de fiabilidade tão consistentes como os da versão original, sendo os coeficientes alpha de Cronbach para os três factores de $.86, .88$, e .82 , respectivamente. No presente estudo, esta versão de 30 itens obteve, no seu total, um alpha de Cronbach de .84, no factor atenção de .70, no factor clareza de .82 e no factor reparação de .69 .

Questionário de Coping com as Emoções Positivas - Pais (OCEP-P, Melo, Moreira \& Soares, 2005). Este questionário avalia o modo como os pais reagem à expressão de emoções positivas dos filhos e foi criado por Melo, Moreira e Soares (2004) a partir do CCNES (Fabes, Eisenberg \& Bernzweig, 1990). À semelhança do CCNE, são apresentadas cinco situações que tendem a gerar emoções positivas nas crianças e pede-se aos pais que imaginem como responderiam à expressão dessas emoções, por parte da sua criança. Para cada item pretende-se que os sujeitos assinalem a frequência com que reagem, ou poderiam reagir a cada uma das afirmações apresentadas nas diferentes situações, segundo cinco diferentes estilos de resposta. Para isso é solicitado aos sujeitos que utilizem uma escala de tipo Lickert, em que 1 corresponde a "muito pouco provável" e 7 a "muito provável". 
As situações apresentadas pretendem, então, avaliar as reacções parentais a cinco emoções positivas manifestadas pela criança, por vezes em situações que poderão conflituar com os interesses dos pais: amor/ternura; orgulho; entusiasmo/ expectativa positiva; alegria; e interesse curiosidade. Neste sentido, as categorias de resposta do OCEP-P representam uma simbiose entre as categorias do CCNES e os estilos parentais descritos por Gottman e DeClaire (1997).

Este questionário permitiu aos autores a identificação de cinco tipos de reacções parentais: as repressivas/inibidoras; as perturbadas/indiferentes; as orientadoras externas/instrumentais; as empáticas/permissivas e as orientadoras capacitadoras. Destes cinco tipos de reacções, foram extraídos três factores: 1) reacções orientadoras/capacitadoras $\left(\alpha_{\text {cronbach }}=.75\right)$ que inclui comportamentos parentais de reconhecimento e orientação da emoção da criança, ajudando-a a pensar sobre a emoção, bem como capacitando-a para a busca de respostas adaptativas, sejam estas orientadas para as soluções ou para as próprias emoções; 2) reacções negativas (incluindo, as repressivas/inibidoras e as indiferentes/perturbadas) que englobam reacções como gozar, minimizar ou punir a criança, bem como demonstrações de desconforto, perturbação ou tentativa de ignorar ou evitar a expressão emocional positiva da criança $\left(\alpha_{\text {cronbach }}=.72\right)$; e 3 ) reacções orientadoras externas/instrumentais $\left(\alpha_{\text {cronbach }}=.64\right)$ que implicam as respostas parentais que procuram lidar com a emoção da criança de forma instrumental, ou seja, utilizando recursos externos como recompensas ou compensações materiais.

No nosso estudo, encontrámos índices de fiabilidade próximos dos apresentados por Melo, Moreira e Soares (2005). Assim, para o QPCE-P total obtivemos um alpha de Cronbach de .67; para o factor reacções negativas, por seu turno, obtivemos um alpha de Cronbach de .83; para as respostas orientadoras externas/instrumentais de .62; e, para o factor respostas orientadores/capacitadoras de .77 .

\section{Resultados}

Este estudo teve como objectivo averiguar a relação entre a expressividade emocional da família de origem, estratégias de regulação emocional e as reacções das mães perante a expressão emocional positiva das suas crianças.

O ambiente de expressividade emocional da família de origem, avaliado pelo FEQ (positivo e negativo) constitui-se como variável preditora, enquanto as reacções maternas negativas, orientadoras/capacitadoras e orientadoras externas/instrumentais avaliadas pelo OCEP se estabeleceram como variáveis dependentes. Em relação às estratégias de regulação emocional (atenção, clareza e reparação) avaliadas pela TMMS, estas foram hipotetizadas como potenciais mediadores 
da relação entre as variáveis anteriormente explicitadas. As correlações produtomomento de Pearson foram realizadas de modo a averiguar as relações entre as variáveis em estudo. Seguidamente, com as análises de regressão linear (método enter) pretendeu-se testar os efeitos mediadores em cada variável dependente em estudo.

Para o efeito efectuámos uma análise estatística baseada nos procedimentos recomendados por Baron e Kenny (1986). Os autores consideram que um efeito mediador total ocorre se a variável preditora se relacionar significativamente (1) com a variável critério; (2) com a variável mediadora e (3) adicionalmente, se a variável mediadora se relacionar com a variável critério, controlando a variável preditora. Para que exista mediação, a relação estatisticamente significativa prévia entre a variável independente e dependente deverá deixar de ser estatisticamente significativa, quando é introduzida a variável mediadora na equação. Por outro lado, um efeito de mediação parcial existe se o efeito da variável independente na dependente é reduzido, quando se introduz o mediador, mas mantém-se diferente de zero.

\subsection{Análise Descritiva}

Relativamente à análise descritiva (c.f. quadro 2) foram calculados os valores das médias e desvio padrão das todas variáveis em estudo (preditoras, mediadores e critério).

Quadro 2. Médias e desvio padrão dos preditores, mediadores e variáveis critério em estudo

\begin{tabular}{lccc}
\hline & M & DP & Intervalo \\
\hline Variáveis Preditoras & & & \\
FEQ Positivo & 6.86 & 1.43 & $2.06-9.0$ \\
FEQ Negativo & 3.50 & 1.36 & $1.0-8.77$ \\
Variáveis Mediadoras & & & \\
TMMS Clareza & 3.99 & 0.61 & $2.09-5.0$ \\
TMMS Atenção & 3.87 & 0.49 & $2.31-4.85$ \\
TMMS Reparação & 4.06 & 0.62 & $2.33-5.0$ \\
Variáveis Critério & & & \\
OQCEP Reacções Negativas & 13.39 & 6.06 & $7.11-36.56$ \\
Q_CEP Reacc̦ões Orientadadoras/ capacitadoras & 25.25 & 3.77 & $10.40-29.40$ \\
O_CEP Reacções Orientadoras externas/Instrumentais & 18.08 & 5.06 & $4.20-28.80$ \\
\hline
\end{tabular}




\subsection{Relação entre a expressividade emocional na família de origem, estratégias de regulação emocional e reacções maternas à expressão das emoções positivas das crianças}

No quadro 3 encontram-se as correlações entre a expressividade emocional positiva e negativa da família de origem, as estratégias de regulação emocional (clareza, atenção e reparação) e as reacções negativas, orientadoras capacitadoras e orientadoras externas instrumentais maternas perante a expressão emocional positiva dos seus filhos.

No que concerne à expressividade emocional positiva verificámos que se encontra correlacionada, de modo estatisticamente significativo, negativamente com as reacções maternas negativas $(r=-.229$, $(p<.01)$ e de modo positivo com as reacções orientadoras capacitadoras ( $r=.371, p<.001)$, mas não com as reacções orientadoras externas/instrumentais. Por seu lado, a dimensão negativa da expressividade emocional familiar apenas obteve correlações significativas com as reacções negativas maternas $(r=.219, p<.01)$. Estes dados parecem sugerir que um ambiente familiar pautado pela validação emocional e de suporte se relaciona com a presença de mais reacções orientadoras capacitadoras e menos reacções negativas por parte das mães, enquanto a expressividade negativa da família de origem se associa a reacções negativas das mães perante a expressão de emoções positivas das suas crianças.

No que diz respeito às estratégias de regulação emocional, as análises de correlações demonstram que todas se correlacionam negativamente e de modo estatisticamente significativo com as reacções negativas à expressão das emoções positivas das crianças, com correlações de $r=-.368$ ( $p<.001)$ para a dimensão clareza, $r=-.323$ ( $p<.001)$ para a atenção e $r=-.365$ ( $p<.001)$ na dimensão reparação. Por outro lado, as dimensões clareza, atenção e reparação correlacionam-se de modo positivo e estatisticamente significativo com as reacções orientadoras capacitadoras ( $r=.309, p<.001 ; r=.309, p<.001 ; r=.264, p<.001$ ) mas não com as reacções orientadoras externas/instrumentais.

Neste sentido, estes resultados evidenciam que as mães que sentem maior clareza em relação às suas emoções, prestam mais atenção e são capazes de reparar os seus estados emocionais, tendem a demonstrar mais reacções orientadoras capacitadoras e menos reacções negativas perante a expressão das emoções positivas das suas crianças. 
Quadro 3. Correlações entre expressividade emocional, estratégias de regulação emocional e reacções maternas às emoções positivas

\begin{tabular}{lcccccccc}
\hline & 1 & 2 & 3 & 4 & 5 & 6 & 7 & 8 \\
\hline $\begin{array}{l}\text { 1.FEQ positivo } \\
\text { 2.FEQ negativo }\end{array}$ & $-.202^{* *}$ & - & - & - & - & - & - & - \\
3.TMMS clareza & $.303^{* * *}$ & $-.229^{* *}$ & - & - & - & - & - & - \\
$\begin{array}{l}\text { 4.TMMS atenção } \\
\text { 5.TMMS reparação }\end{array}$ & $.297^{* * *}$ & .023 & $.533^{* * *}$ & - & - & - & - & - \\
$\begin{array}{l}\text { 6.O_CEP reacções } \\
\text { negativas }\end{array}$ & $-.289^{* * *}$ & $-.178^{*}$ & $.520^{* * *}$ &, $334^{* * *}$ & - & - & - & - \\
$\begin{array}{l}\text { 7.OCEP reacções orien- } \\
\text { tadoras capacitadoras }\end{array}$ & $.219^{* *}$ & $-.368^{* * *}$ & $-.323^{* * *}$ &,$- 365^{* * *}$ & - & - & - \\
$\begin{array}{l}\text { 8. OCEP reacções ori- } \\
\text { entadoras externas/ }\end{array}$ & -.035 &, $309^{* * *}$ &, $309^{* * *}$ &, $264^{* * *}$ & $-.445^{* * *}$ & - & - \\
instrumentais & .093 & .144 & -.046 & -.148 & -.043 & $.160^{*}$ & $.156^{*}$ & - \\
\hline
\end{tabular}

${ }^{* * *} p<.001 ;{ }^{* *} p<.01 ;{ }^{*} p<.05$

3.3. O efeito mediador da regulação emocional na relação entre expressividade emocional na família de origem e reacções maternas à expressão de emoções positivas das crianças

Seguimos as indicações do modelo de regressão linear sugerido por Baron e Kenny (1986) de modo a testar o efeito mediador das estratégias de regulação emocional (clareza, atenção e reparação).

\section{Expressividade emocional negativa na família de origem}

3.3.1 Estudo do efeito mediador das estratégias de regulação emocional (clareza e reparação) na relação entre expressividade emocional negativa e reacções maternas negativas à expressão de emoções positivas da criança

Pretendemos indagar se a clareza apresenta um efeito mediador na relação entre a expressividade emocional familiar negativa e as reacções negativas maternas face à expressão de emoções positivas das suas crianças (c.f. quadro 4). Assim, procedemos a uma análise de regressão linear de modo a constatar se a expressividade emocional negativa da família de origem (VI) explica a variável critério (reacções maternas negativas). Dos resultados verificou-se que a VI explica 4,8\% da variância das reacções maternas negativas $(\beta=.219 ; p<.01)$. Em seguida, pretendemos averiguar se a variável preditora explicava o potencial mediador clareza 
( $\beta=-.229 ; p<.01)$, o que se verificou, explicando $5,2 \%$ da variância do mesmo. Por seu lado, a variável mediadora revelou explicar $13 \%$ da variância das reacções maternas negativas $(\beta=-.368 ; p<.001)$.

Quadro 4. Efeito mediador da clareza na relação entre a expressividade emocional familiar negativa e as reacções negativas às emoções positivas da criança (VD)

\begin{tabular}{|c|c|c|c|c|c|c|c|}
\hline VI & B & $\beta$ & $\mathrm{t}$ & $R$ & $\mathrm{R}^{2}$ & F change & $p$ \\
\hline \multirow[t]{2}{*}{ FEQ negativo } & .978 & .219 & $2.903^{* *}$ & & & & \\
\hline & & & & .219 & .048 & 8.427 & .004 \\
\hline \multirow[t]{2}{*}{ FEQ negativo } & -.102 & -.229 & $-3.039^{* *}$ & & & & \\
\hline & & & & .229 & .052 & 9.235 & .003 \\
\hline \multirow[t]{2}{*}{ TMMS clareza } & -3.679 & -.368 & $-5.113^{* * *}$ & & & & \\
\hline & & & & .368 & .135 & 26.144 & .000 \\
\hline FEQ negativo/ & .635 & .142 & 1.943 & & & & \\
\hline \multirow[t]{2}{*}{ TMMS clareza } & -3.353 & -.335 & $-4.574^{* * *}$ & & & & \\
\hline & & & & .393 & .155 & 15.176 & .000 \\
\hline
\end{tabular}

${ }^{* * *} p<.001 ;{ }^{* *} p<.01 ;{ }^{*} p<.05$

O modelo final revelou-se significativo com a expressividade emocional negativa e a clareza, introduzidas como variáveis independentes, a explicarem 15,5\% da variância da variável critério, sendo que a expressividade emocional perde o seu poder, deixando de ser significativa ( $\beta=.142 ; p>.05$ ). Assim, podemos considerar que o efeito da expressividade emocional negativa da família de origem nas reacções negativas maternas à expressão de emoções positivas é totalmente mediado pela capacidade das mães compreenderem as suas emoções (clareza emocional).

De modo semelhante, e após a constatação que a VI explica a variável critério, efectuou-se uma análise de regressão linear, com o intuito de averiguar se a variável preditora explicava a estratégia de reparação emocional (mediador). Efectivamente, a expressividade emocional negativa explica 3,2\% da variância da reparação ( $\beta=-.178 ; p<.05)$. No que concerne ao mediador verificou-se que explica $13,3 \%$ da variância da variável critério $(\beta=-.365 ; p<.001)$.

No modelo final de regressão verificou-se a existência de um efeito de mediação parcial da reparação emocional na relação entre o ambiente negativo de expressividade emocional na família de origem e as reacções negativas maternas. Deste modo, podemos afirmar que a vivência, na infância, num ambiente familiar de expressividade emocional negativa e hostil tem efeitos directos e indirectos (através do seu efeito na capacidade das mães repararem os seus estados emocionais) nas reacções negativas que as mães apresentam aquando da expressão emocional positiva dos seus filhos (c.f. quadro 5). 
Quadro 5. Efeito mediador da reparação na relação entre a expressividade emocional familiar negativa e as reacções negativas às emoções positivas da criança (VD)

\begin{tabular}{|c|c|c|c|c|c|c|c|}
\hline $\mathrm{VI}$ & $\mathrm{B}$ & $\beta$ & $\mathrm{t}$ & $R$ & $\mathrm{R}^{2}$ & F change & p \\
\hline \multirow[t]{2}{*}{ FEQ negativo } & .978 & .219 & $2.903^{* *}$ & & & & \\
\hline & & & & .219 & .048 & 8.427 & .004 \\
\hline \multirow[t]{2}{*}{ FEQ negativo } & -.082 & -.178 & $-2.337^{*}$ & & & & \\
\hline & & & & .178 & .032 & 5.462 & .021 \\
\hline \multirow[t]{2}{*}{ TMMS reparação } & -3.542 & -.365 & $-5.062^{* * *}$ & & & & \\
\hline & & & & .365 & .133 & 25.626 & .000 \\
\hline FEO negativo/ & .711 & .159 & $2.201^{*}$ & & & & \\
\hline \multirow[t]{2}{*}{ TMMS reparação } & -3.267 & -.336 & $-4.647^{* * *}$ & & & & \\
\hline & & & & .397 & .158 & 15.529 & .000 \\
\hline
\end{tabular}

${ }^{* * *} \mathrm{p}<.001 ;{ }^{* *} \mathrm{p}<.01 ;{ }^{*} \mathrm{p}<.05$

\section{Expressividade emocional positiva na família de origem}

\subsubsection{O efeito mediador das estratégias de regulação emocional na relação entre expressividade emocional positiva e reacções maternas negativas à expressão de emoções positivas da criança}

De modo a averiguar o hipotetizado efeito mediador das estratégias de regulação (clareza, atenção e reparação emocional) na relação entre o ambiente de expressividade emocional positiva na família de origem e as reacções maternas negativas à expressão de emoções positivas das crianças, efectuaram-se análises de regressão linear simples, como proposto por Baron e Kenny (1986).

Primeiramente pretendeu-se indagar se a preditora explica a variável critério, facto que se revelou significativo, explicando a expressividade emocional positiva na família de origem $5,2 \%$ da variância da VD ( $\beta=-.229 ; p<.01)$. Deste modo, as análises evidenciam que a vivência na infância num ambiente familiar pautado pelo suporte e expressão emocional positiva se associa a menos reacções negativas das mães face à expressão de emoções positivas das suas crianças (cf. Quadro 6).

Seguidamente, efectuámos análises de regressão linear independentes com o objectivo de testar o efeito mediador de cada uma das estratégias de regulação emocional.

No que diz respeito à clareza (cf. Quadro 6), esta é explicada pela variável preditora em 9,2\% ( $\beta=.303 ; p<.001)$. Concomitantemente, a clareza explica em 13,5\% a variância da variável critério $(\beta=-.368 ; p<.001)$.

O modelo final da equação explicou 15,1\% da variância das reacções maternas, sendo estatisticamente significativo, e comprovando a existência de um efeito mediador total, uma vez que a expressividade emocional familiar positiva deixou de 
ser significativa $(\beta=-.129 ; p>.05)$ quando se introduziu a clareza. Os dados obtidos evidenciam que o ambiente familiar de expressividade emocional positiva funciona como um factor protector indirecto das reacções negativas maternas, uma vez que potencia o desenvolvimento da capacidade das mães compreenderem as emoções.

438 Quadro 6. Efeito mediador da clareza na relação entre a expressividade emocional familiar positiva e as reacções negativas às emoções positivas da criança (VD)

\begin{tabular}{|c|c|c|c|c|c|c|c|}
\hline $\mathrm{VI}$ & B & $\beta$ & $\mathrm{t}$ & $R$ & $R^{2}$ & F change & $p$ \\
\hline \multirow[t]{2}{*}{ FEQ positivo } & -.965 & -.229 & $-3.036^{* *}$ & & & & \\
\hline & & & & .229 & .052 & 9.220 & .003 \\
\hline \multirow[t]{2}{*}{ FEQ positivo } & .128 & .303 & $4.108^{* * *}$ & & & & \\
\hline & & & & .303 & .092 & 16.872 & .000 \\
\hline \multirow[t]{2}{*}{ TMMS clareza } & -3.679 & -.368 & $-5.113^{* * *}$ & & & & \\
\hline & & & & .368 & .135 & 26.144 & .000 \\
\hline FEQ positivo/ & -.545 & -.129 & -1.720 & & & & \\
\hline \multirow[t]{2}{*}{ TMMS clareza } & -3.228 & -.329 & $-4.380^{* * *}$ & & & & \\
\hline & & & & .388 & .151 & 14.705 & .000 \\
\hline
\end{tabular}

${ }^{* * *} p<.001 ;{ }^{* *} p<.01 ;{ }^{*} p<.05$

Em relação à atenção (cf. Quadro 7), verificámos que é explicada pela variável preditora em $8,8 \%$ ( $\beta=.297$; $p$ <.001) e que, por seu lado, explica 10,5\% da variância da variável critério ( $\beta=-.323 ; p<.001)$. Por fim, no modelo final da equação em que introduzimos a expressividade emocional positiva e a clareza como variáveis independentes, o referido modelo revelou-se estatisticamente significativo, explicando $12,4 \%$ da variância das reacções maternas negativas, obtendo-se um efeito mediador total. Assim, verificou-se que a expressividade emocional positiva deixou de ser significativa $(\beta=-.146 ; p>.05)$ no modelo quando o mediador é introduzido. Este facto significa que a influência da expressividade emocional familiar positiva na ausência de reacções negativas maternas passa totalmente pela capacidade das mães prestarem atenção às emoções.

Quadro 7. Efeito mediador da atenção na relação entre a expressividade emocional familiar positiva e as reacções negativas às emoções positivas da criança (VD)

\begin{tabular}{|c|c|c|c|c|c|c|c|}
\hline VI & B & $\beta$ & $\mathrm{t}$ & $R$ & $\mathrm{R}^{2}$ & F change & $p$ \\
\hline \multirow[t]{2}{*}{ FEQ positivo } & -.965 & -.229 & $-3.036^{* *}$ & & & & \\
\hline & & & & .229 & .052 & 9.220 & .003 \\
\hline \multirow[t]{2}{*}{ FEQ positivo } & .101 & .297 & $4.023^{* * *}$ & & & & \\
\hline & & & & .297 & .088 & 16.183 & .000 \\
\hline TMMS atenção & -4.019 & -.323 & $-4.4 .15^{* * *}$ & & & & \\
\hline & $\begin{array}{l}-.614 \\
-3.481\end{array}$ & $\begin{array}{l}-.146 \\
-.280\end{array}$ & $\begin{array}{c}-1.912 \\
-3.680^{* * *}\end{array}$ & .323 & .105 & 19.489 & .000 \\
\hline TMMS atenção & & & & .352 & .124 & 11.728 & .000 \\
\hline
\end{tabular}

${ }^{* * *} p<.001 ;{ }^{* *} p<.01 ;{ }^{*} p<.05$ 
De igual modo, foi nosso objectivo averiguar a existência de um efeito mediador da reparação emocional na relação entre a expressividade emocional positiva da família e as reacções negativas das mães face à expressão das emoções positivas das crianças (c.f. quadro 8).

Após a constatação de que a VI explica significativamente a variável critério, fomos averiguar se também explica o potencial mediador (cf. quadro 8). Esta análise revelou-se significativa com a variável preditora a explicar $8,4 \%$ da variância do mediador ( $\beta=.289, p<.001$ ). Do mesmo modo, a variável mediadora revelou-se explicativa de $13,3 \%$ da variância das reacções negativas maternas $(\beta=-.365, p<.001)$.

Finalmente, obteve-se o efeito mediador total no modelo final de equação. Assim, o modelo final explicou $15 \%$ da variância da variável critério, sendo que a expressividade emocional positiva deixou de ser significativa $(\beta=-.134, p>.05)$ quando a variável reparação entrou na equação. Podemos afirmar que existe um efeito indirecto (pela acção da capacidade materna em reparação os estados emocionais) da expressividade emocional positiva da família de origem nas reacções maternas negativas.

Quadro 8. Efeito mediador da reparação na relação entre a expressividade emocional familiar positiva e as reacções negativas às emoções positivas da criança (VD)

\begin{tabular}{lccccccc}
\hline VI & $\mathrm{B}$ & $\beta$ & $\mathrm{t}$ & $\mathrm{R}$ & $\mathrm{R}^{2}$ & $\mathrm{~F}$ change & $\mathrm{P}$ \\
\hline FEQ positivo & -.965 & -.229 & $-3.036^{* *}$ & & & & \\
FEQ positivo & .126 & .289 & $3.904^{* * *}$ & .229 & .052 & 9.220 & .003 \\
& & & & .289 & .084 & 15.243 & .000 \\
TMMS reparação & -3.542 & -.365 & $-5.062^{* * *}$ & & & & \\
& & & & .365 & .133 & 25.626 & .000 \\
FEQ positivo/ & -.567 & -.134 & -1.799 & & & & \\
TMMS reparação & -3.164 & -.326 & $-4.358^{* * *}$ & & & & \\
& & & & .387 & .150 & 14.602 & .000 \\
\hline
\end{tabular}

${ }^{* * *} p<.001 ;{ }^{* *} p<.01 ;{ }^{*} \mathrm{p}<.05$

Na globalidade, verificou-se o efeito mediador das estratégias de regulação emocional. Estes resultados indicam-nos que o efeito da expressividade positiva da família de origem nas reacções negativas das mães perante a expressão de emoções positivas das crianças depende na sua totalidade do desenvolvimento das capacidades maternas de prestar atenção, compreender (clareza) e reparar os estados emocionais. 


\subsubsection{O efeito mediador das estratégias de regulação emocional na relação entre expressividade emocional familiar positiva e reacções maternas orientadoras capacitadoras}

De modo semelhante ao anteriormente explicitado procedeu-se à averiguação do efeito mediador das estratégias de regulação emocional (clareza, atenção e reparação emocional) na relação entre o ambiente de expressividade emocional positiva e as reacções maternas orientadoras capacitadoras à expressão emocional positiva dos filhos.

Neste sentido, a expressividade emocional familiar positiva revelou-se significativa, explicando a $12,1 \%$ da variância da VD ( $\beta=.348$; $p<.01)$, o que significa que a existência na infância de um ambiente de expressividade emocional marcadamente positiva e de suporte emocional está associado a mais reacções maternas que incluem o reconhecimento da emoção e a orientação na procura de respostas eficazes para regular as emoções positivas das suas crianças (cf. Quadro 9).

Partindo da premissa anterior, pretendeu-se explorar o efeito mediador de cada uma das estratégias de regulação emocional de modo independente, recorrendo a análises de regressão linear.

Em relação à clareza (cf. Quadro 9), esta é explicada pela variável preditora em $9,2 \%$ ( $\beta=.303 ; p<.001)$, explicando, por seu turno, $9,6 \%$ da variância da variável critério $(\beta=.309 ; p<.001)$..

Quadro 9. Efeito mediador da clareza na relação entre a expressividade emocional familiar positiva e as reacções orientadoras capacitadoras às emoções positivas da criança (VD)

\begin{tabular}{lccccccc}
\hline VI & $\mathrm{B}$ & $\beta$ & $\mathrm{t}$ & $\mathrm{R}$ & $\mathrm{R}^{2}$ & F change & $\mathrm{P}$ \\
\hline FEQ positivo & .914 & .348 & $4.798^{* * *}$ & & & & \\
FEO positivo & .128 & .303 & $4.108^{* * *}$ & .348 & .121 & 23.021 & .000 \\
& & & & .303 & .092 & 16.872 & .000 \\
TMMS clareza & 1.924 & .309 & $4.201^{* * *}$ & & & & \\
& & & & .309 & .096 & 17.650 & .000 \\
FEQ positivo/ & .735 & .280 & $3.768^{* * *}$ & & & & \\
TMMS clareza & 1.396 & .224 & $3.018^{* *}$ & & & & \\
& & & & .408 & .167 & 16.622 & .000 \\
\hline
\end{tabular}

${ }^{* * *} p<.001 ;{ }^{* *} p<.01 ;{ }^{*} p<.05$

O modelo final foi estatisticamente significativo, explicando $16,7 \%$ da variância das reacções maternas orientadoras capacitadoras. Contudo, não se verificou o efeito de mediador, mas sim efeitos independentes das variáveis (expressividade emocional positiva e clareza), uma vez ambas se mantém significativas na explicação da variável critério. 
Replicaram-se os procedimentos com a dimensão atenção das estratégias de regulação emocional (cf. Quadro 10). Os dados obtidos permitem verificar que a atenção é explicada pela variável preditora em 8,8\% ( $\beta=.297$; $p<.001)$ e que explica $9,6 \%$ da variância da variável critério ( $\beta=-.309 ; p<.001)$. Quando introduzimos a expressividade emocional positiva e a clareza como variáveis independentes no modelo final de regressão, este revelou-se estatisticamente significativo, explicando $16,8 \%$ da variância da variável dependente. Deste modo, verificaram-se efeitos independentes de ambas as variáveis na explicação das reacções maternas orientadoras capacitadoras que incluem comportamentos que auxiliam a criança a identificar, reconhecer e regular de modo adaptativo as suas emoções positivas.

Quadro 10. Efeito mediador da atenção na relação entre a expressividade emocional familiar positiva e as reacções orientadoras capacitadoras às emoções positivas da criança (VD)

\begin{tabular}{lccccccc}
\hline VI & $\mathrm{B}$ & $\beta$ & $\mathrm{t}$ & $\mathrm{R}$ & $\mathrm{R}^{2}$ & $\mathrm{~F}$ change & $\mathrm{p}$ \\
\hline FEQ positivo & .914 & .348 & $4.798^{* * *}$ & & & & \\
FEQ positivo & .101 & .297 & $4.023^{* * *}$ & .348 & .121 & 23.021 & .000 \\
& & & & .297 & .088 & 16.183 & .000 \\
TMMS atenção & 2.392 & .309 & $4.202^{* * *}$ & & & & \\
FEQ positivo/ & .738 & .281 & $3.789^{* * *}$ & .309 & .096 & 17.655 & .000 \\
TMMS atenção & 1.746 & .226 & $3.043^{* *}$ & & & & \\
& & & & .409 & .168 & 16.710 & .000 \\
\hline
\end{tabular}

${ }^{* * *} p<.001 ;{ }^{* *} \mathrm{p}<.01 ;{ }^{*} \mathrm{p}<.05$

Quadro 11. Efeito mediador da reparação na relação entre a expressividade emocional familiar positiva e as reacções orientadoras capacitadoras às emoções positivas da criança (VD)

\begin{tabular}{lccccccc}
\hline VI & $\mathrm{B}$ & $\beta$ & $\mathrm{t}$ & $\mathrm{R}$ & $\mathrm{R}^{2}$ & $\mathrm{~F}$ change & $\mathrm{P}$ \\
\hline FEQ positivo & .914 & .348 & $4.798^{* * *}$ & & & & \\
FEQ positivo & .126 & .289 & $3.904^{* * *}$ & .348 & .121 & 23.021 & .000 \\
& & & & .289 & .084 & 15.243 & .000 \\
TMMS reparação & 1.594 & .264 & $3.534^{* * *}$ & & & & \\
& & & & .264 & .070 & 12.487 & .000 \\
FEQ positivo/ & .778 & .297 & $3.968^{* * *}$ & & & & \\
TMMS reparação & 1.075 & .178 & $2.381^{*}$ & & & & \\
& & & & .388 & .150 & 14.668 & .000 \\
\hline
\end{tabular}

${ }^{* * *} p<.001 ;{ }^{* *} \mathrm{p}<.01 ;{ }^{*} \mathrm{p}<.05$

Finalmente, realizámos o mesmo procedimento para a dimensão reparação emocional (c.f. quadro 11). Assim, a referida dimensão ( $\beta=.289, p<.001)$, é explicada em $8,4 \%$ pela variável preditora. Seguidamente, verificou-se que a variável mediadora se revelou explicativa de $7 \%$ da variância das reacções maternas orientadoras capacitadoras ( $\beta=.264, p<.001$ ). No modelo de equação final obtiveram-se efeitos 
independentes das variáveis. O modelo final explicou 15\% da variância da variável critério, sendo que tanto a expressividade emocional positiva como a reparação emocional se mantiveram significativas na explicação da VD.

Em conclusão, verificou-se a existência de efeitos independentes do ambiente familiar, na infância, de expressividade positiva e das estratégias de regulação emocional na explicação das reacções orientadoras capacitadoras das mães aquando da expressão emocional positiva das suas crianças. Neste sentido, podemos afirmar que vivenciar, na infância, um ambiente familiar de expressividade emocional de suporte e validação emocional constitui-se como o melhor preditor das reacções maternas de auxílio ao reconhecimento e procura de estratégias funcionais de regulação das emoções positivas das crianças.

\section{Discussão}

Este estudo conceptualizou-se como um acréscimo à investigação tentando compreender qual o efeito que a expressividade emocional durante a infância têm no modo como na adultez, estas mães tendem a socializar as emoções das crianças através das reacções perante a expressão emocional positiva das suas crianças. Paralelamente, foi nosso objectivo averiguar o efeito mediador das estratégias de regulação emocional maternas na relação entre o ambiente familiar de expressividade emocional na família de origem e o modo como as mães tendem a responder aos seus filhos quando estes expressam emoções positivas.

Em síntese, constatou-se a existência de um efeito transgeracional de socialização das emoções, sendo que as mães que, na infância, experienciaram ambientes de expressividade emocional marcadamente positiva apresentam maiores níveis de clareza, atenção e capacidade de reparação dos estados emocionais, reagindo de modo mais construtivo à expressão de emoções positivas das suas crianças.

Os resultados obtidos corroboram a nossa hipótese inicial, verificando-se que a existência de um ambiente familiar de expressividade predominante positiva se associa ao menor uso de respostas negativas e tendência para responder de modo orientador capacitador perante a expressão de emoções positivas das crianças. Por outro lado, a tendência materna para reagir negativamente às emoções positivas das crianças associou-se a ambientes familiares de expressividade emocional negativos e hostis.

No que concerne à regulação emocional, os resultados evidenciam que as mães que sentem maior clareza em relação às suas emoções, prestam mais atenção e são capazes de reparar as suas emoções, tendem a demonstrar mais reacções orienta- 
doras capacitadoras e menos reacções negativas de minimização, desconforto ou punição perante a expressão das emoções positivas das suas crianças, ajudando-as a reconhecer, diferenciar e regular os seus estados emocionais positivos.

O ambiente familiar de expressividade emocional negativa revelou efeitos directos e indirectos (através do seu efeito na capacidade das mães compreenderem e repararem os seus estados emocionais) nas reacções negativas que as mães apresentam aquando da expressão emocional positiva dos seus filhos. Isto significa que as mães que na sua infância experienciaram ambientes de expressão emocionalmente negativa, em que as emoções eram conceptualizadas como ameaçadoras ou perturbadoras, tendem, na adultez, a revelar menor capacidade de compreensão e reparação dos seus estados emocionais e a reagir às emoções positivas dos seus filhos de modo mais negativo, utilizando comportamentos como desvalorizar, punir ou minimizar a expressão emocional destes.

As estratégias de regulação emocional funcionaram, como mediadores totais da relação entre um ambiente emocionalmente positivo na família de origem e as reacções negativas maternas à expressão de emoções negativas dos seus filhos. Este resultado indica que viver num ambiente familiar pautado pela emocionalidade positiva e de suporte parece não ser um factor protector directo das reacções negativas das mães, mas a sua acção reflecte antes efeitos indirectos, através das capacidades que as mães desenvolveram para prestarem atenção, compreenderem e repararem os seus estados emocionais. Assim, estas experiências precoces parecem ter permitido a estas mães desenvolver um maior conhecimento e regulação emocional, reconhecendo a importância da validação emocional e apresentando melhores competências e práticas parentais mais positivas para lidar com as emoções dos filhos

Por outro lado, a existência de um ambiente de expressividade emocional positiva na infância constituiu-se como o melhor preditor das reacções maternas que espelham comportamentos de ajuda à identificação, reconhecimento e regulação emocional das emoções positivas das crianças, funcionando como um factor protector de relevância.

Não obstante, este estudo apresenta algumas limitações que importa ter em consideração. Neste sentido, existe alguma margem de possibilidade de contaminação dos dados recolhidos, uma vez que não foi utilizada uma medida de desejabilidade social. Concomitantemente, não foram controladas as variáveis temperamento das crianças e personalidade das mães. Deste modo, consideramos que seja possivel que as respostas de algumas mães perante a expressão emocional das suas crianças se relacionem com o temperamento mais difícil da criança e não tanto com as suas estratégias de regulação emocional. De modo 
idêntico, a personalidade materna pode influenciar o modo como estas socializam as emoções das crianças, tal como tem sido sugerido na literatura.

Concluindo, esta investigação é, tanto quanto é do nosso conhecimento, a primeira a demonstrar a existência do efeito transgeracional de socialização das emoções, focando-se nas emoções positivas que tem sido, de algum modo, negligenciadas na investigação. A existência, durante a infância, de um ambiente familiar pautado pela validação e suporte emocional parece ter uma função protectora quer directa quer indirectamente, pelas capacidades maternas em compreenderem, prestarem atenção e repararem os estados emocionais, no modo como as mães tendem a responder às emoções positivas dos filhos, usando mais o suporte emocional e auxiliando as suas crianças a identificar, distinguir, validar e regular as suas emoções.

\section{Referências bibliográficas}

Baker, J.K., \& Crnic, K.A. (2005). The relation between mother's reports of family-of-origin expressiveness and their emotion-related parenting. Parenting: Science and Practice, 5(4), 333-346.

Baron, R.M, \& Kenny, D.A. (1986). The moderator-mediator variable distinction in social psychological research: Conceptual, strategic, and statistical considerations. Journal of Personality and Social Psychology, 51, 1173-1182.

Campbell-Sills, L. \& Barlow. D.H. (2007). Incorporating Emotion Regulation into Conceptualizations and Treatments. In J. J. Gross (Ed.). Handbook of emotion regulation (542-559). New York: The Guildford Press.

Cole, P.M., Martin, S.E., \& Dennis, T.A. (2004). Emotion regulation as a scientific construct: Methodological challenges and directions for child development research. Child Development, 75(2), 317-333.

Denham, S. A., Mitchell-Copeland, J., Strandberg, K., Auerbach, S., \& Blair, K. (1997). Parental contributions to preschoolers' emotional competence: Direct and indirect effects. Motivation \& Emotion, 21 (1), 65-86).

Dinis, A., Pinto Gouveia, J., \& Xavier, A., (2010). Family Expressivity Questionnaire. Manuscrito submetido a publicação. Disponível com os autores. Coimbra: FPCE/ Universidade de Coimbra.

Dunsmore, J.C., \& Halberstadt, A.G. (1997). How does family emotional expressiveness affect children's schemas. New Directions for Child Development, 77, 45-68.

Eisenberg, N., Champion, C., \& Ma, Y. (2004). Emotion-related regulation: An emerging construct. Merrill-Palmer Quarterly, 50(3), 236-259.

Eisenberg, N., Cumberland, A., \& Spinrad, T.L. (1998). Parental Socialization of Emotion. Psychol Inq. 9(4), 241-273.

Eisenberg,N., Fabes, R.A.,Murphy, B.C. (1996). Parents' reactions to children's negative emotions: Relations to children's social competence and comforting behavior. Chil Development, 67, 2227-2247. 
Eisenberg, N., Fabes, R.A., Shepard, S.A., Guthrie, I.K., Murphy, B.C., \& Reiser,M. (1999). Parental reactions to children's negative emotions: Longitudinal relations to quality of children's social functioning. Child Development, 70, 513-534.

Eisenberg, N., Gershoff, E.T., Fabes, R. A., Shepard, S.A., Cumberland, A. J., Losoya, S.H., Guthrie, I.K., \& Murphy, B.C. (2001). Mothers' emotional expressivity and children's behavior problems and social competence: Mediation through children's regulation. Developmental Psychology, 37(4), 475-490.

Eisenberg, N., \& Spinrad, T.L. (2004). Emotion-related regulation: Sharpening the definition. Child Development, 75(2), 334-339.

Eisenberg, N., Valiente, C., Morris, A.S., Fabes, R.A., Cumberland, A.J., Reiser, M., Gershoff, E.T., Shepard, S.A.,\& Losoya, S.H. (2003). Longitudinal relations among parental emotion expressivity, children's regulation, and quality of socioemotional functioning. Developmental Psychology, 39(1), 3-19.

Fabes, R.A., Eisenberg, N., \& Bernzweig, J. (1990). The coping with children's negative emotions scale: Procedures and scoring. Available from authors. Arizona State University.

Fabes, R. A., Leonard, S. A., Kupanoff, K., \& Martin, C. L. (2001). Parental coping with children's negative emotions: Relations with children's emotional and social responding. Child Development, 72(3), 907-920.

Gilbert, P., Cheung, M.S.P., Grandfield, T., Campey, F., \& Irons, C. (2003). Recall of threats and submissiveness in childhood: Development of a new scale and its relationship with depression, social comparison and shame. Clinical Psychology and Psychotherapy, $10,108-115$.

Gottman, J.M., \& DeClaire, J. (1997). The Heart of Parenting: Raising an Emotionally Intelligent Child. New York: Simon \& Schuster Inc.

Gottman, J. M., Katz, L. F., \& Hooven, C. (1996). Parental Meta-Emotion Philosophy, and the Emotional Life of Families: Theoretical Models and Preliminary Data. Journal of Family Psychology,10(3),243-268.

Gratz, K.L. \& Roemer, L. (2004). Multidimensional Assessment of Emotion Regulation and Dysregulation: Development, Factor Structure, and Initial Validation of the Difficulties in Emotion Regulation Scale. Journal of Psychopathology and Behavioral Assessment, 26(1), 41-54

Gross, J.J. (1998). The emerging Field of Emotion Regulation: An Integrative Review. Review of General Psychology, 2(3), 271-299.

Gross, J.J., Richards, J.M., \& John, O.P. (2006) Emotion regulation in Everyday Life (pp. 13-35). In D.K. Snyder, J.A. Simpson \& J.N. Hudges (Eds.). Emotion regulation in couples and families: Pathways to Dysfuntion and Health. Washington, DC: American Psychological Association.

Halberstadt, A. G. (1986). Family socialization of emotional expression and nonverbal communication styles and skills. Journal of Personality and Social Psychology, 51(4), 827-836.

Melo, A. (2005). Emoções no periodo escolar: Estratégias parentais face à expressão emocional e sintomas de internalização e externalização da criança. Tese de Mestrado em Psicologia Clínica não publicada. Braga: FPCE/Universidade do Minho.

Melo, A., Moreira, P., \& Soares, I. (2004). Questionário de Coping com Emoções Positivas-Pais. Disponível com os autores. Instituto de Educação e Psicologia, Universidade do Minho.

Mikolajczak, M., Nelis, D., Hansenne, M., \& Quoidbach, J. (2008). If you can regulate sadness, you can probably regulate shame: Associations between trait-emotional intelligence, 
emotion regulation and coping efficiency across discrete emotions. Personality and Individual Differences, 44, 1356-1368.

Parker, A.E. (2006). Parental socialization of positive and negative emotions: Associations with children's everyday coping and display rule knowledge. A dissertation submitted to the Graduate Faculty of North Carolina State University.

Perlman, S.B., Camras, L.A., \& Pelphrey, K.A. (2008). Physiology and functioning: Parents' vagal tone, emotion socialization, and children's emotion knowledge. Journal of Experimental Child Psychology, 100, 308-315.

Pinto Gouveia, J., \& Dinis, A., (2006). Trait Meta-Mood Scale. Manuscrito não publicado. Disponivel com os autores. Coimbra: FPCE/ Universidade de Coimbra.

Roberts, W., \& Strayer, J. (1987). Parents' responses to the emotional distress of their children: Relations with children's competence. Developmental Psychology, 23(3), 415-422.

Salovey, P., Mayer, J. D., Goldman, S. L., Turvey, C., \& Palfai, T. P. (1995). Emotional attention, Clarity, and Repair: Exploring emotional intelligence using the Trait Meta-Mood Scale. In J. W. Pennebaker (Ed). Emotion disclosure, and health (pp. 125-154). Washington, D.C.: American Psychological Association.

Simpson, J.A., Hughes, J.N., \& Snyder, D.K. (2006). Introduction: Cross-disciplinary approaches to emotion regulation. In D.K. Snyder, J.A. Simpson \& J.N. Hudges (Eds.). Emotion regulation in couples and families: Pathways to Dysfuntion and Health. Washington, DC: American Psychological Association.

Valiente, C., \& Eisenberg, N. (2006). Parenting and Children's Adjustment: The Role of children's Emotion Regulation. In D.K. Snyder, J.A. Simpson \& J.N. Hudges (Eds.). Emotion regulation in couples and families: Pathways to Dysfuntion and Health. Washington, DC: American Psychological Association (pp.123-142).

\section{The mediaton effect of the emotional regulation in the relation of family-of-origin expressivity and mothers reactions to the expression of children's positive emotions}

The fundamental role of the family, especially that of the parents, as the main agents of the socialization of emotions, has been highlighted throughout research. From an early onset, parental practices are a model for the identification and understanding of emotions, for learning the emotional expression and regulation strategies. This study examines the mediaton effect of the strategies for emotion regulation used by mothers of 169 children from 8 to 12 years, in the relation between their recollections of their family-of-origin expressiveness and the way they react to the positive emotional expressiveness of their children. We found evidence for the existence of a transgenerational effect on the process of socialization of emotions, in that the mother's strategies for emotional regulation work as a mediation effect of the relation between the emotional expressiveness of the mother's family-of-origin and the maternal reactions to the positive emotional expression of their children.

KEY-WORDS: Family expressivity; Emotion socialization; Emotional regulation; Mothers' reactions. 
L'effet médiateur de la régulation émotionnel dans la relation entre

l'expression émotionnelle de la famille d'origine e les réactions des mères à l'expression émotionnelle positif de leurs enfants.

La rôle fondamental de la famille, en particulier celle des parents, comme les principaux agents de la socialisation des émotions, a été mis en évidence dans la recherche. Dès tôt, les pratiques parentales sont un moyen privilégié pour l'identification et la compréhension des émotions, pour l'apprentissage de l'expression émotionnelle et des stratégies de régulation. Cette étude examine l'effet médiateur des stratégies de régulation émotionnelle de 169 mères d'enfants de 8 à 12 ans, dans la relation entre l'expressivité de leurs familles d'origine et la façon dont elles réagissent aux émotions positives de leurs enfants. Les résultats montrent l'existence d'un effet transgénérationnel du processus de socialisation des émotions, ayant les stratégies de régulation émotionnelle des mères un effet de médiation dans la relation entre l'expression émotionnelle de la famille d'origine et les réactions de la mère à l'expression émotionnelle positive de leurs enfants.

MOTS-CLÉS: L'expressivité de la famille ; Socialisation des émotions ; Régulation émotionnelle ; Les réactions des mères 